\title{
The word-superiority effect does not require a $\mathrm{T}$-scope
}

\author{
WILLIAM PRINZMETAL \\ University of California, Berkeley, California
}

\begin{abstract}
Six experiments examined the possibility of obtaining a word-superiority effect (WSE) without the use of brief stimulus exposures or a poststimulus mask. In each experiment, subjects were presented a stimulus string and two alternative strings that differed by $a$ single letter (Reicher, 1969). The alternatives and stimulus remained in view until subjects responded, and subjects were under no pressure to respond quickly. In Experiments 1-3, the stimuli were presented in very small type so that they were difficult to see. Subjects were significantly more accurate with words than with nonwords, letters embedded among digits, or letters embedded among number signs (\#s). In Experiments 4 and 5, the stimuli were embedded in a simultaneously present pattern mask. Subjects were significantly more accurate with words than with single letters by themselves. In the final experiment, the stimuli were presented in a mask with specific spatial frequency characteristics, and performance was significantly better with words than with nonwords. The WSE is a more general phenomenon than previously supposed; it is not limited to a tachistoscopic exposure.
\end{abstract}

Experiments in which visual stimuli are briefly presented in order to limit performance are ubiquitous in experimental psychology. Instruments used to briefly present stimuli have included the electric spark generator, the gravity chronometer (Cattell, 1885), an oil lantern behind a photographic shutter (Pillsbury, 1897), the tachistoscope, the point plotter, and the raster display of the familiar personal computer. Generically, these devices are known as T-scopes. Volumes of research have been based on the use of T-scopes, in one form or another.

Despite the preponderance of this research, a few skeptics have questioned whether the results of T-scope experiments are informative about perception in more naturalistic settings. For example, Dodge (1907) likened studying vision with a brief exposure to perception in a thunderstorm. He contended not only that the results would fail to generalize to more naturalistic situations, but that the use of too brief an exposure would result in "making the conclusions not merely valueless but false" (p. 32). Katz (1925/1989) complained that the frequent use of the T-scope led to a "tachistoscopic mentality." A more modern iconoclast, who was showing visitors his laboratory, is reported to have pointed to the room housing the tachistoscope and to have commented, "the devil lives there." It is true that we are rarely called upon to read briefly presented stimuli, except perhaps in a thunderstorm or in a discotheque with stroboscopic lighting.

Nevertheless, research with brief exposures has led to many important findings, and so it may be rash to deni-

This research was supported by NIMH Grant MH39881 to W. Prinzmetal. I would like to thank Richard Ivry and Beth Silvers for their helpful comments on the manuscript. Correspondences concerning this article should be addressed to William Prinzmetal, care of Department of Psychology, University of California, Berkeley, CA 94720. grate this research. One of the best known of these findings, which is the subject of this paper, is Reicher's (1969) discovery of the word-superiority effect (WSE). Reicher briefly presented words, nonwords, or single-letter stimuli, followed by a visual noise mask. Subjects had to determine which of two alternative letters was present in the display. For example, the alternative letters might be $\mathbf{N}$ or L. For the word stimuli, both alternative letters would form an English word, such as WIND or WILD. Since both alternative letters formed a word, the subjects could not improve their performance by guessing an alternative that formed a word. The subjects were significantly more accurate with the words than with the nonwords or even with single letters. Thus the WSE is really composed of two different effects: the word-nonword effect and the word-letter effect. As will be suggested later, although both aspects of the WSE are almost always explained by a single theory, they may arise from different causes.

Reicher's (1969) results seem to indicate that word perception involves more than the identification of individual letters. For word stimuli, the other stimulus letters facilitate recognition of the target letter. Yet one might still question the generality of the WSE, for it has always been found with brief exposures. The goal of the present study was to test whether one could obtain a WSE without the use of brief exposures. In all of the experiments, the stimuli remained in view until the subjects responded, and the subjects were under no pressure to respond quickly. As in Reicher's original experiment, two-alternative forcedchoice accuracy was the dependent variable.

At least some of the stimulus conditions employed in this work were similar to situations that are encountered in everyday life. For example, in Experiments 1-3, the stimuli were presented with very small letters, just as we often must read signs from a distance. However, the main 
advantage of the present research is not that the situations were somehow more "ecologically valid" than those in previous work. Rather, the goal was simply to explore the generality of the WSE. Several theories attribute the WSE effect to presentation conditions that are specific to tachistoscopic presentation (e.g., Johnston, 1981; Johnston \& McClelland, 1973). Although an account of the WSE with tachistoscopic presentation is interesting, an account that could be applied to word perception in general would be much more interesting.

Some indications suggest that brief presentation is not necessary for a WSE. For example, Krueger and his colleagues have found that search for a target letter in lists of words is faster than search through lists of nonwords (Krueger, 1970; Krueger, Keen, \& Rublevich, 1974; Krueger \& Shapiro, 1979). However, reaction time tasks may measure processes that are different from those that are measured in tasks in which accuracy is a dependent variable (see, e.g., Santee \& Egeth, 1980). Furthermore, subjects may engage in different processing strategies in the typical WSE and search reaction time experiments. In the reaction time paradigm, performance is typically better when the target is in the beginning of a letter string (e.g., B. A. Eriksen \& C. W. Eriksen, 1974; Krueger, 1975), whereas in the typical WSE experiment, performance is typically better when the target is in the middle of a letter string (see, e.g., Rumelhart \& McClelland, 1982). Thus, it is not certain that a WSE would be obtained with accuracy as the dependent variable without a brief exposure.

If a WSE can be obtained without brief stimulus exposures, a number of questions can be asked about word perception that cannot be addressed in experiments that are done with brief exposures or even with reaction time as a dependent variable. Some of these questions will be suggested later. However, before these additional questions can be addressed, it will be necessary to determine whether a WSE can be obtained without a brief stimulus exposure. This was the goal of the present study. In the experiments that follow, word-letter and word-nonword effects were sought in three different stimulus situations: (1) small letters viewed from a distance (Experiments 1-3); (2) stimuli embedded in a simultaneously present pattern mask (Experiments 4-5); and (3) stimuli embedded in a simultaneously present statistically defined mask (Experiment 6 ).

\section{EXPERIMENT 1}

We are often called upon to read signs from a distance. For example, when I first moved to Santa Barbara, I was looking for the freeway exit for Carrillo Street. Unfor- tunately, I knew that within a short distance from Carrillo Street, there was also a street called Cabrillo Street. I knew that one of the streets exited from the right lane, and the other from the the left lane, but I could not recall whether Carrillo exited from the right or the left. In the distance, I saw a sign indicating a right-lane exit. Because the freeway was crowded, I had to decide from quite far away whether the sign said Carrillo or Cabrillo. Essentially, I was faced with Reicher's task: I had to decide whether the third letter was an R or a B. Experiments 1-3 essentially simulated this situation. In these experiments, it was asked whether or not it is easier to discriminate letters, viewed from a distance, when they are in a context that forms a word. ${ }^{1}$

The first experiment compared four-letter words, nonwords, and single letters that were embedded in randomly chosen digits. The nonwords were anagrams of the words. As in previous investigations, the single letters were embedded among other characters to equate for lateral masking (see, e.g., Bjork \& Estes, 1973; Johnston \& McClelland, 1973; Marchetti \& Mewhort, 1986). The reason for using digits is that it is sometimes found that target letters are detected better in a background of digits than in a background of other letters (see, e.g., Gleitman \& Jonides, 1978; Jonides \& Gleitman, 1972). Hence, letters among digits should provide a conservative comparison.

\section{Method}

Each subject participated in a single 1-h session. The stimuli were presented in very small print at the center of a monitor, one at a time, and the two alternatives were presented in larger print on either side of each stimulus (see Figure 1). The subject was instructed to indicate, by pressing one of two buttons, whether the small stimulus in the middle of the display matched the alternative on the right or the one on the left. Investigators have discussed whether the alternatives should come on before or after the stimulus (e.g., Bjork \& Estes, 1973; Thompson \& Massaro, 1973); in the present instance, the stimuli and the alternatives remained in view until the subject responded. The subjects were instructed to take as much time as was necessary for them to make their responses.

Each subject was tested on two blocks of 288 trials. The order of the stimuli was randomly determined for each subject and block. Whether a particular alternative appeared to the left or to the right of the stimulus was also randomly determined on each trial. Feedback was given only at the end of each block.

Stimuli. The stimuli consisted of 96 four-letter words, 96 nonwords, and 96 letters among digits. The words are listed in the Appendix. Each of 48 pairs of words differed by a single, critical target letter. Each letter position was used equally often for the target letter. The nonwords were created by scrambling the letters in the words so that the target letters remained in the same positions, and the resulting strings resembled English words as little as possible. The letters among digits contained the target letter and three randomly chosen digits, excluding 0 and 1 . Examples consisting of a word, a nonword, or a letter among digits are WIND, DWNI, 
and $94 \mathrm{~N} 7$, respectively. The stimulus was flanked on either side by alternatives that differed by a single letter (e.g., WIND-WILD; DWNI-DWLI; 94N7-94L7).

The displays were presented on a Macintosh 13-in. monitor controlled by a Macintosh II computer, at a viewing distance of $244 \mathrm{~cm} .{ }^{2}$ The displays were black on a white background with a resolution of 72 pixels per inch (approximately 28 pixels per centimeter). The stimuli appeared in Helvetica 9-point type, and the alternatives were in Helvetica 36-point type. The small stimulus strings subtended $0.256^{\circ}$ of visual angle in width.

Subjects. Fifteen subjects, recruited from the undergraduate and graduate student population at the University of Oregon, were paid $\$ 5$ for participating. In all of the experiments reported in this paper, the subjects were approximately evenly divided between females and males. All had normal or corrected-to-normal vision. The data from 3 of the subjects were not included in the analysis because they were correct on over $96 \%$ of the trials.

\section{Results and Discussion}

The results are shown in Figure 2. The subjects were more accurate with words than with nonwords or letters among digits. The mean percentages correct for words, nonwords, and letters among digits were $89.7 \%, 85.8 \%$, and $85.1 \%$, respectively. The difference was reliable both with subjects as the random variable $[F(2,22)=19.012$, $p<.001]$ and with items as the random variable $[F(2,276)$ $=5.865, p<.005]$. Every subject made fewer errors on words than on the other stimuli averaged together.

As can be seen in Figure 2, the difference between the three stimulus types was larger for the two center positions than for the outer positions. However, the interaction between the target letter position and the other positions was marginally reliable with subjects as the random variable $[F(6,66)=2.118, p=.06]$, and it did not approach significance with items as the random variable $[F(6,276)$ $=.808$ ]. Because of possible ceiling effects for the end letter positions, it is difficult to interpret this type of interaction.

The subjects were significantly more accurate when the target letter was in the outer positions. The $F$ ratios for the target position were $F(3,33)=16.06$ and $F(3,276)$

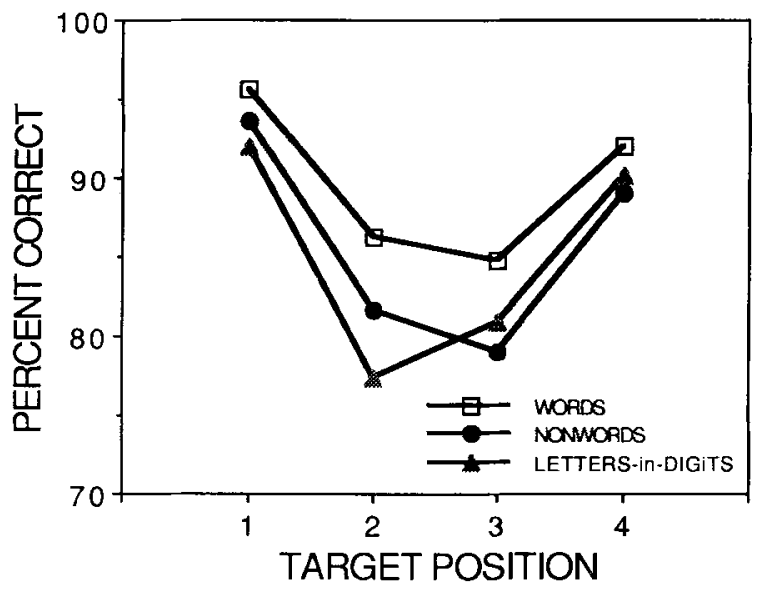

Figure 2. Comparison of results from Experiment 1 for words, nonwords, and letters embedded among digits.
$=28.75$ for subjects and items as the random variables, respectively (both $p s<.001$ ).

Finally, the subjects were not significantly more accurate at detecting letters in nonwords than in letters among digits (cf. Gleitman \& Jonides, 1978; Jonides \& Gleitman, 1972). The difference between nonwords and letters among digits was not reliable with either subjects or items as the random variable $[t(11)=0.88$ and $t(95)=.57$, respectively]. The reason for not obtaining a category effect is not clear. It may be that the unlimited exposure time used in the present experiment will not lead to a difference between searching for a letter among letters and searching for a letter among digits. Alternatively, it could be that the font used in the present experiment does not have a feature structure that would enable subjects to efficiently classify characters as letters or digits (Duncan, 1983; Hock, Rosenthal, \& Stenquist, 1985).

Although the advantage for words was consistent, the magnitude of the effect was in the low end of the range of previous WSE studies. For example, Reicher (1969) found about an $8 \%$ advantage for words over single letters and nonwords (single-string condition). Johnston and McClelland (1973) found a $13.4 \%-16.4 \%$ advantage for words over single letters. However, Baron and Thurston (1973) found only a 4.8\% advantage for words over unpronounceable strings, which is similar to the magnitude of the present effect.

Perhaps it is surprising that there was a WSE at all. Johnston and McClelland (1974) found that when subjects were told the target position in advance and were asked to attend only to an individual letter, performance for words actually declined. Thus, with words, it might be possible to attend to individual letters rendering words functionally equivalent to nonwords (also see, e.g., Johnston, 1981a; Paap \& Newsome, 1980). Certainly, under the conditions in the present experiment, subjects knew which position contained the target letter, and they had plenty of time to focus attention on that letter. It might be that there is a limit to the size of attentional focusing (see, e.g., C. W. Eriksen \& Hoffman, 1973). Alternatively, before subjects are able to focus their attention to the target letter in a word, they may pick up enough information about the nontarget letters to assist processing. Finally, subjects may, at least on some trials, not attempt to focus attention on individual letters, but process the words as a whole.

\section{EXPERIMENT 2}

In Experiment 2, performance on words was compared with performance on letters embedded among number signs (e.g., READ and \#E\#\#). The comparison of words with letters among digits employed in Experiment 1 has not been previously employed in a WSE experiment with brief exposure, but with a brief exposure, investigators have found performance to be better on words than on letters embedded among \#s (e.g., Johnston \& McClelland, 1973).

The second major difference between this experiment and Experiment 1 was that the alternatives were presented 
Figure 3. A sample stimulus from Experiment 2.

in a cursive font that was very different from the stimulus font (Zapf Chancery 36 point vs. Helvetica 9 point; see Figure 3). Because the stimulus and alternatives were simultaneously in view in Experiment 1, the subjects could have based their responses on a template match between the stimulus and alternatives. It might be that this type of matching is easier for words than letters. If different fonts are used for the alternatives and the stimulus, such a template match is unlikely.

There were a few other differences between Experiment 2 and Experiment 1. In Experiment 2, the subjects made their responses orally, responding with a whole word (on word trials) or the single letter (on trials with letters embedded among \#s). The trial type (word vs. letters among \#s) was alternated between block, with half the subjects beginning with words. There were 6 blocks of trials and 96 trials per block. All subjects were initially seated at a distance of $213 \mathrm{~cm}$ from the monitor, so that the stimuli subtended a visual angle of $0.256^{\circ}$. If on the first pair of blocks, a subject exceeded $90 \%$ correct, the viewing distance was increased to $244 \mathrm{~cm}$ so that the stimuli subtended $0.224^{\circ}$. Twelve subjects, recruited from the subject pool at the University of California, Santa Barbara, participated in this experiment.

\section{Results}

The subjects were significantly more accurate with words than with letters among \#s (89.0\% vs. $84.2 \%)$. This difference was reliable both with subjects as the random variable and with items as the random variable $[F(1,11)$ $=27.35$ and $F(1,184)=8.73$, respectively, both $p s<$ $.005]$. As can be seen in Figure 4, the subjects were more accurate in the end positions than in the center positions. The effect of position was reliable both with subjects and

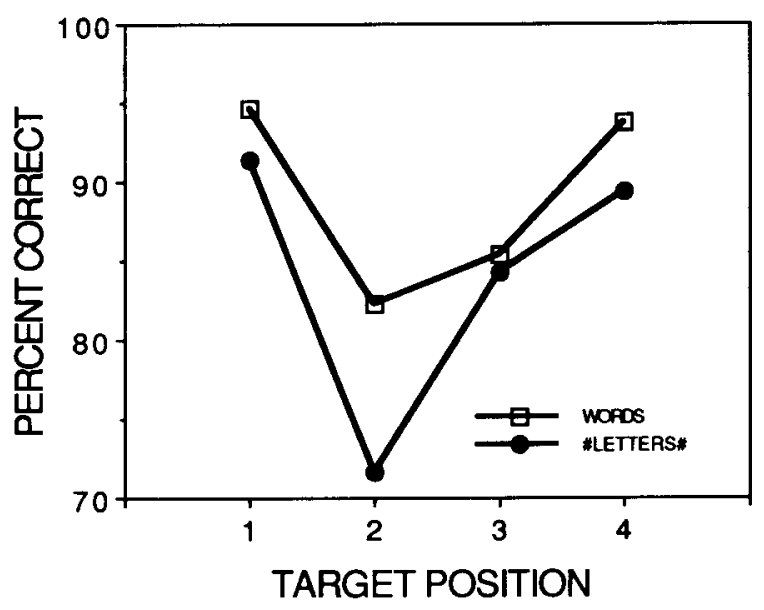

Figure 4. Comparison of results from Experiment 2 for words and letters embedded among \# signs. with items as the random variables $[F(3,33)=23.11$ and $F(3,184)=20.39$, respectively, both $p s<.005]$. Finally, the difference between words and letters embedded among \#s was greater for some positions than for others (see Figure 4). However, the interaction between stimulus type and target position was reliable only with subjects as the random variable $[F(3,33)=6.03, p<.005]$. With items as the random variable, the interaction was not reliable $[F(3,148)=1.48]$.

\section{EXPERIMENT 3}

In one possibly critical respect, Experiments 1 and 2 were different from the typical WSE experiment with brief exposures. In the usual experiment, only the single letters are given as alternative responses, not the entire stimulus string. In Experiment 3, only single letters were presented as alternatives, and the stimuli consisted of words and letters embedded among \#s. So that the subjects would know the location of the target letter, the alternative letters were embedded in + signs. Thus, the small stimulus word ROAD was presented simultaneously with the large alternatives $+\mathrm{O}++$ and $+\mathrm{E}++$, and the small stimulus \#O\#\# was presented with the large alternatives $+\mathrm{O}++$ and $+\mathrm{E}++$. As in the previous experiments, the alternatives flanked the stimulus and remained in view until the subject responded. The alternatives appeared in Helvetica 36-point type, and the stimulus was in Helvetica 9 point. The viewing distance was adjusted as in Experiment 2 .

In addition to guessing the target letter, the subjects were instructed on word trials to guess the whole word if they could. There were two reasons for having the subjects try to respond with the whole word. First, I wanted to ensure that the subjects were encoding the words as wholes. As was previously discussed, Johnston and McClelland (1974) demonstrated that subjects could ignore words and attend to individual letters; attending to individual letters reduced performance on word trials. Second, by having the subjects guess the words, one could determine the conditional probability of responding with the correct target letter when the word was not correct. It might be that subjects demonstrate a WSE only when they can identify the word as a whole. Alternatively, only partial information from context letters may suffice. The subjects made the two responses verbally (letter and word) in whatever order they wanted, and the stimulus remained in view until they made both responses. The subjects were forced to respond with a letter alternative, but they were not forced to respond with a word. An advantage of using unlimited exposure is that there is no memory limitation. Subjects can make many responses to the stimulus without fear that the stimulus will fade in some iconic representation before the response is made. In all other respects, this experiment was identical to Experiment 2. 


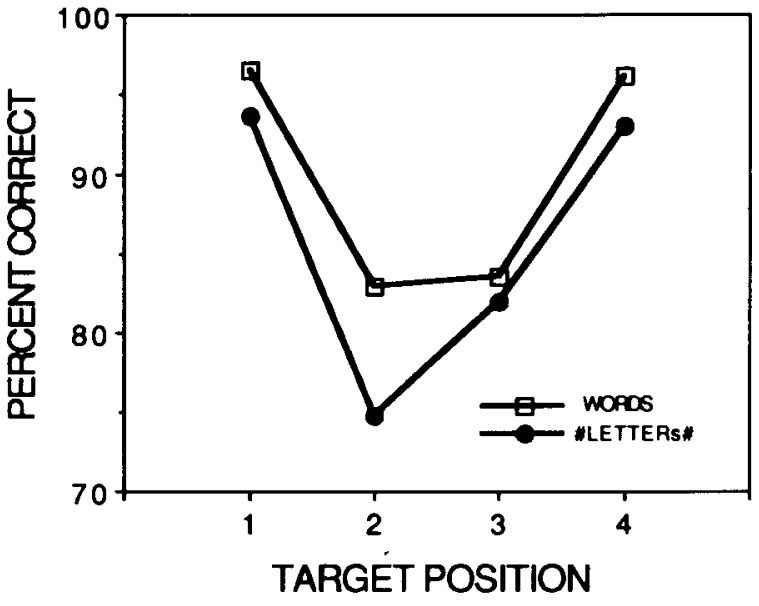

Figure 5. Comparison of results from Experiment 3 for words and letters embedded among \# signs.

\section{Results}

The results were almost identical to those of the previous experiments (see Figure 5). The subjects were more accurate on words than on letters embedded among \#s $(89.8 \%$ vs. $85.8 \%)$. This difference was reliable with both subjects and items as random variables $[F(1,11)=9.72$ and $F(1,184)=4.74$, respectively, both $p s<.05]$. Performance was better with targets in the outer positions, and this effect was also reliable with both subjects and items as the random variables $[F(3,33)=37.55$ and $F(3,184)=20.66$, both $p s<.001]$. The interaction of stimulus type and target position was not reliable with either subjects or items as the random variable $[F(3,33)$ $=1.98$ and $F(3,184)=0.66$, respectively].

The data from word trials were subjected to an additional analysis. For each subject, I calculated the probability of a correct letter response, given an incorrect or no-word response (i.e., $p[L \mid \sim W]$ ). The mean of this conditional probability was less than the probability of getting a correct letter response on trials with letters among \#s $(0.798$ vs. 0.858$)$. This difference was reliable $[t(11)$ $=3.52, p<.005]$. One interpretation of this difference is that when subjects cannot correctly identify the word, they will not show a WSE. It might seem surprising that $p(L \mid \sim W)$ was significantly less than the probability of a correct letter response on trials with letter among \#s. However, the a priori probability of correctly guessing a word was much less than that of correctly guessing a letter, and anything that lowered the probability of getting the word correct would probably lower $p(L \mid \sim W)$. Nevertheless, the possibility of asking how much nontarget information is necessary for the WSE seems hopeful, because, in the present paradigm, one can ask subjects not only to identify a particular target letter, but also about the perception of other letters without fear of overloading short-term memory or the stimulus fading in an iconic store.

\section{EXPERIMENT 4}

Experiments 1-3 demonstrated that subjects were better at detecting letters embedded in words rather than in nonwords, among digits, or among number signs. These results were obtained without brief exposures, pressure to respond quickly, or a poststimulus pattern mask. The latter observation is important, because some theories of the WSE postulate that a visual poststimulus pattern mask is necessary for the WSE to be obtained (e.g., Johnston, 1981b; Johnston \& McClelland, 1980).

Yet although a mask may not be necessary for a WSE (see Marchetti \& Mewhort, 1986), a mask might have a differential effect on words or other stimuli. For example, Johnston and McClelland (1973) found an approximately $15 \%$ advantage of words over single letters with a pattern mask, but without a mask, there was a $2 \%$ ad-

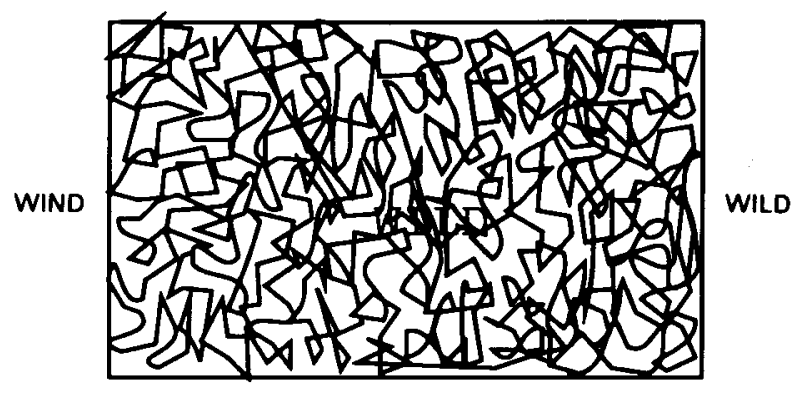

$\mathbf{N}$

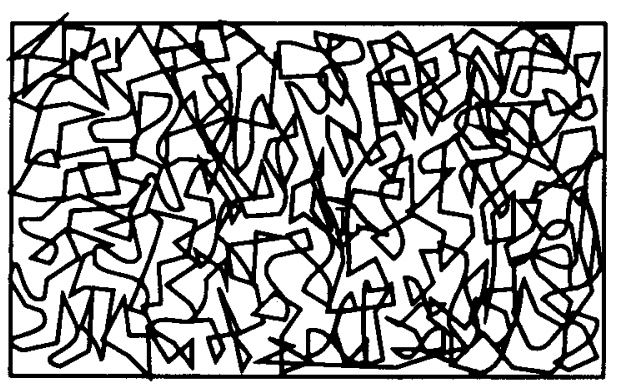

L

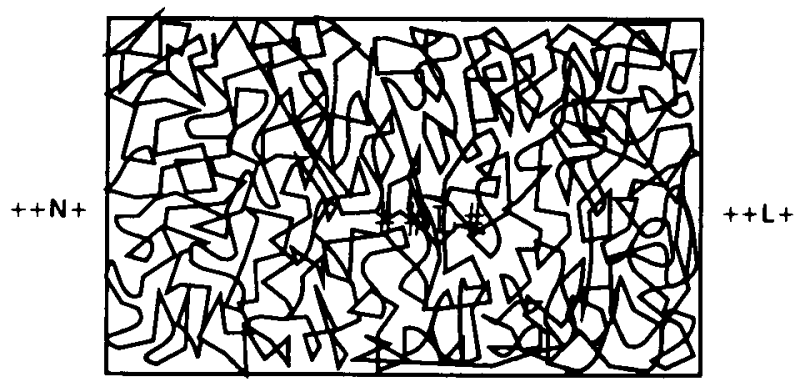

Figure 6. Sample stimuli in Experiment 4. 
vantage for letters. To equate overall performance in the mask and no-mask conditions, the contrast was reduced in the no-mask condition. It is important to note that Johnston and McClelland obtained a word advantage over letters embedded among \#s even in the no-mask condition.

An important condition was omitted from Experiments 1-3. Performance with words was never compared with performance with letters alone (i.e., without number signs or digits). In the conditions of Experiments 1-3, pilot observations made it clear that performance was clearly better with letters alone than with words. Hence, perhaps a visual mask is necessary to find an advantage for words over letters presented alone.

With brief exposures and a poststimulus mask, it is difficult to determine how the mask affects processing (C. W. Eriksen, 1980). There are at least two kinds of theories of backward masking: interruption theories and integration theories. Interruption theories claim that the mask terminates ongoing processing, thereby erasing the stimulus (e.g., Turvey, 1973). For example, Johnston and McClelland (Johnston, 1981b; Johnston \& McClelland, 1973) have proposed that a backward mask sets up a wave of activation that nullifies the activity in feature detectors. With nonwords and single letters, letter detectors only receive input from feature detectors, and this input has been wiped out by the mask. With words, on the other hand, letter detectors also receive input from lexical units.

Integration theories, in contrast, claim that a mask affects performance by forming a montage with the stimulus (e.g., C. W. Eriksen \& Collins, 1967, 1968). The amalgamation of the mask and stimulus is due to relatively poor temporal resolution in the visual system. If the mask forms a montage with the stimulus, single-letter performance could be affected in at least two ways. Without a mask, target letters in words, in nonwords, and among \#s will suffer some degree of lateral masking, but letters alone will not. If the mask sums with the stimulus, single letters will also be surrounded by contours causing lateral masking (see Figure 6). Thus, a mask might remove an advantage that letters alone would otherwise enjoy. Lateral masking is not dependent on a brief exposure (e.g., Banks, Larson, \& Prinzmetal, 1979; Bouma, 1973; Flom, Weymouth, \& Kahneman, 1963; Loomis, 1978; Townsend, Taylor, \& Brown, 1971; Woodworth, 1938).

A mask might also create a figure-ground problem, making a single letter more difficult to find (Leeper, 1935). In order to identify the target, subjects must isolate the target (figure) from the mask (ground). Single letters may be more difficult to find in a mask than words, simply because it is often easier to find a large object than a small object. The nontarget letters in a word would help locate the target. Thus, without assuming that a mask erases anything, there are several reasons why a mask might be necessary for performance to be better with words than with letters alone.

Fortunately, with unlimited exposure, it becomes possible to isolate the effect of integration masking by presenting the mask simultaneously with the target. If performance with words is better than performance with

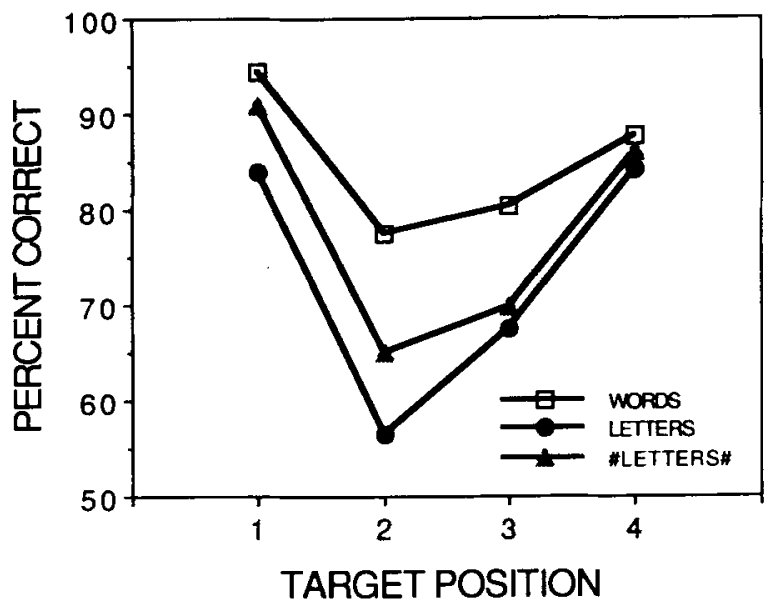

Figure 7. Comparison of results from Experiment 4 for words, letters embedded among \# signs, and single letters.

letters alone, it is not necessary to postulate that the mask interrupts processing, or sets up a wave of activation, to explain the word-letter effect.

\section{Method}

In Experiment 4, words, single letters, and single letters embedded among \#s were used. Examples of the three types of stimuli are WIND, \#\#\#, and __ N _ (the _ denotes a space). The stimuli were simultaneously presented at the center of the pattern mask shown in Figure 6. The mask was drawn to be similar to the mask used by Johnston and McClelland (1973). The stimuli were drawn in Courier 18-point type, and the alternatives were in Helvetica 24point type. Courier type was used for the stimuli because it was used by Johnston and McClelland with a similar mask. Because Courier type is not proportionally spaced or kerned, the location of the target letter was exactly the same for all three types of stimuli.

Twelve subjects viewed the displays from $213 \mathrm{~cm}$ so that fourletter stimulus strings subtended $0.426^{\circ}$ of visual angle in width. There were two blocks of 96 trials per block for each of the three stimulus types. The order of the blocks was random, with the constraint that each stimulus type occur once in the first three blocks and once in the last three blocks. Also, across subjects, each stimulus type occurred for 2 subjects in the first block, second block, third block, etc. The subjects responded verbally with the critical letter in nonword trials and with a word alternative in word trials. In all other aspects, the experiment was identical to Experiments 2 and 3.

\section{Results}

The percentages correct for words, letters among \#s, and single letters were $85.0 \%, 77.9 \%$, and $73.1 \%$, respectively. The difference was reliable with both subjects and items as the random variable $[F(2,22)=30.11$ and $F(2,276)=13.86$, respectively, both $p$ s $<.001]$. All 12 subjects had fewer errors on words than on the other stimuli, and fewer errors on letters among \#s than on single letters. It is possible to obtain a word-single-letter effect with a mask without postulating interruption masking.

As can be seen in Figure 7, the difference between the stimulus types was greater for the center target positions than for the end positions, and this interaction was reliable with subjects as the random variable $[F(6,66)=5.77$, 
$p<.001$ ], but not with items as the random variable $[F(6,276)=1.48]$. The subjects were more accurate for targets in the end positions, and target position was reliable both with subjects and with items as the random variable $[F(3,33)=68.65$ and $F(3,276)=34.96$, respectively, both $p s<.001]$.

\section{EXPERIMENT 5}

An anomalous result in Experiment 4 was the finding that the target position affected performance for the singleletter stimuli. It is reasonable to expect that performance would be worse for the center positions for words and letters among \#s because these positions would have more lateral masking than targets in the end positions (e.g., Banks et al., 1979; Flom et al., 1963; Loomis, 1978; Townsend et al., 1971; Woodworth, 1938). However, there was no reason to expect that the single letters in the "center positions" would have worse performance than the end positions, because these target letters were surrounded by spaces. An examination of the displays revealed that the center letters for all stimulus types fell on locations in the mask with particularly dense contours. Thus the position effect may have been due to an idiosyncrasy of the displays. One goal of Experiment 5 was to examine this possibility.

The second goal of Experiment 5 was to test the generality of the advantage of words over letters embedded among other characters. In Experiment 4, letters were embedded among \#s. The reason for embedding letters among other symbols was to equate the amount of lateral masking. With a simultaneously presented mask, it was not necessary to embed single letters among other symbols to obtain a word-letter effect. In fact, in Experiment 4, embedding single letters among \#s improved performance relative to the use of single letters alone. Perhaps this was because the number signs made the target letter easier to find. However, before one claims that letters embedded in other characters will be easier than single

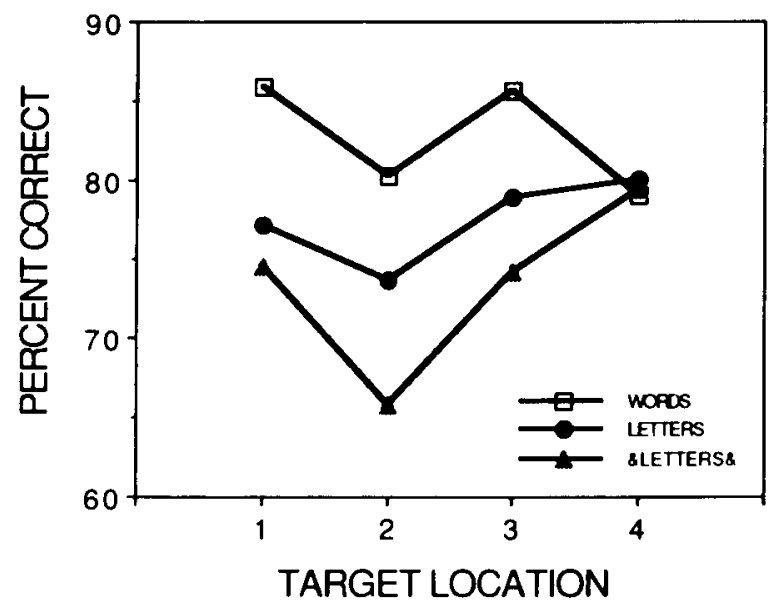

Figure 8. Comparison of results from Experiment 5 for words, letters embedded among $\&$ signs, and single letters. letters alone, it is prudent to compare performance on single letters with performance on single letters embedded among instances of another symbol (e.g., \&\&L\&).

\section{Method}

Experiment 5 was identical to Experiment 4 except for the following factors. In Experiment 5, words, single letters, and single letters embedded among ampersands (\&) were used. Four masks were created by rotating and reflecting the mask used in Experiment 4 . The mask was randomly chosen on each trial. The position of the stimulus string was randomly varied horizontally \pm 11 pixels in single-pixel steps ( 11 pixels was the width of one character).

\section{Results and Discussion}

The percentages correct for words, letters among \&s, and single letters were $82.7 \%, 73.4 \%$, and $77.4 \%$, respectively (see Figure 8). The difference was reliable both with subjects and with items as the random variable $[F(2,22)=$ 15.25 and $F(2,276)=11.50$, respectively, both $p s<$ $.001]$. Every subject but 1 had fewer errors on words than on the other two stimulus types averaged together.

Unlike in Experiment 4, however, the subjects were not more accurate on letters embedded in other characters than on single letters alone (cf. Figures 7 and 8). Ten of 12 subjects were more accurate on single letters than on letters among \&s. The different results of Experiments 4 and 5 call into question the practice of embedding single letters among other characters to equate single letters to words. Different results may be obtained, depending on what type of character the experimenter chooses to use for embedding the single-letter targets. There are at least three factors to consider when one chooses the nontarget characters. The similarity of the single-letter target and nontarget character should equal the average similarity of the target and the nontarget letters in words. The nontarget characters should exert the same amount of lateral masking as do the nontarget letters in words. Finally, the padding character should match the nontarget letters in words in its ability to help locate the target letter.

It is unlikely that an experimenter will be able to control all of these factors. The ampersands in Experiment 5 may have contributed some degree of lateral masking, but they were not conspicuous enough to help subjects locate the target letter. It is possible that single letters, embedded in some other characters, might actually be easier to see than letters in words. In a pilot experiment, I found that accuracy was higher with a letter embedded among dark circles (i.e., bullets: $\bullet N \bullet$ ) than with words. Thus the practice of comparing words with single letters embedded in some other character should probably be avoided.

As can be seen in Figure 8, there was a small interaction of target position and stimulus type. The difference between the stimulus types was greater for the center target positions than for the end positions, and this interaction was reliable with subjects as the random variable $[F(6,66)=6.05, p<.001]$, but not with items as the random variable $[F(6,276)=1.58, p>.15]$. The only stimulus type to show a significant position effect with both words and items as random variables consisted of letters among \&s $[F(3,33)=13.63$ and $F(3,276)=4.22$, 
respectively, both $p s<.005]$. The effect of target position for single letters in Experiment 4 was apparently an artifact of the particular stimulus displays that were used.

Experiments 4 and 5 demonstrate that one can obtain a word-[single]-letter effect without brief exposures by embedding the single letters in a simultaneously present pattern mask. It is not necessary to postulate that a mask must interrupt processing for a word-letter effect to be obtained. In these experiments, the mask formed a montage with the stimulus, simulating integration masking. It was postulated that the effect of the mask was to equate letters in words and single letters for lateral masking. Alternatively, the mask might create a figure-ground problem, making the single letters difficult to locate.

Two pieces of evidence suggest that the word-letter effect is due to the mask's making it difficult to find a single target letter. First, in Experiment 4, the addition of \#s to single letters improved performance. Phenomenally, it was easier to find the target when it was embedded among \#s than when it was presented alone, or than when it was embedded in \&s (at least with Courier font). Second, Johnston (1981a) briefly presented words or single letters followed by a pattern mask. He found a robust word-letter effect. However, when he precued the position of the target letter, performance was better with single letters.

The word-nonword effect may behave differently from the word-single-letter effect. The nontarget letters in a nonword should make it as easy to find the target in the mask as it is to find the target in a word. Evidence from the use of brief exposures suggests that this may be the case. Paap and Newsome (1980) found that the wordnonword effect was not eliminated by the use of a position precue. Thus the cause of the word-nonword and wordsingle-letter effects might be different. However, it will be necessary to compare words, nonwords, and single letters with an integration mask-with and without a position cue-within a single experiment.

\section{EXPERIMENT 6}

Experiment 1 demonstrated that one can obtain a wordnonword difference with small stimuli viewed at a distance without brief exposures. It is also possible to obtain a word-letter difference with small stimuli, provided that the single letters are flanked by other characters. However, pilot data indicated that it was not likely that small words would be perceived better than single letters by themselves. Experiments 4 and 5 showed that words are perceived better than single letters when simultaneously presented with a visual noise mask. In the final experiment, it was asked whether it would be possible to obtain a word-nonword difference with simultaneous masking. To test the generality of the WSE without brief exposures, a slightly different procedure and mask were employed.

On each trial, subjects were presented three-letter words or nonwords. They had to make three separate twoalternative forced-choice responses. Thus, presented with the stimulus RUT, the subjects had to determine whether the first letter was $\mathbf{R}$ or $\mathbf{P}$, the second letter $\mathbf{A}$ or $\mathrm{U}$, and the third letter $\mathrm{T}$ or $\mathrm{N}$. All the alternatives formed words (e.g., PAN, PUN, PAT, etc.; see Chastain, 1986). The nonwords were formed by permuting the letter alternatives in words. Hence, for each nonword trial, the subjects had to determine whether the first letter was $\mathbf{N}$ or $T$, the second letter $R$ or $P$, and the third letter $A$ or $U$. Thus, each trial yielded three responses.

The mask that was used is shown in Figure 9. It was created by beginning with visual white noise; each pixel was assigned a random brightness value from 1 to 256 . This image was then lowpass filtered (i.e., blurred). It was thus possible to create a mask with specific spatial frequency characteristics.

\section{Method}

Procedure. The subjects participated in three blocks of 50 word trials and three blocks of 50 nonword trials. The blocks were alternated, and half the subjects began with word trials. Before beginning each block, the subjects were given a sheet of paper with the eight possible word stimuli (PAN, PUN, PAT, PUT, RAN, RUN, RAT, RUT) or the eight possible nonword stimuli (NPA, NRA, NPU, NRU, TPA, TRA, TPU, TRU). The list was available throughout the block. The subjects were told that there were two-alternative letter responses for each position. For word trials, the subjects verbally responded with a whole word. For nonword trials, the subjects verbally spelled the nonword. The stimulus for each trial was randomly selected. The stimuli remained in view until the subjects finished responding, and the subjects were under no time pressure to respond quickly. Feedback was given at the end of each block. Twelve subjects, from the same subject pool as that used in Experiments 2-5, participated in a single $45-$ min session.

Stimuli. The stimuli were simultaneously presented with a mask (see Figure 9) on a standard 13-in. Macintosh color monitor (72 pixels per inch). The mask was created in the following way (see Figure 9). A white-noise image was created on a Macintosh II computer with the program DIP Station (Hayden Image Processing Group). The image was then filtered with the program Image (National Institutes of Health) to remove frequencies lower than .18 cycles per pixel.

The stimuli were presented in condensed Geneva 14-point type and viewed from a distance of $152 \mathrm{~cm}$. The three-letter stimuli subtended a visual angle of approximately $0.39^{\circ}$ in a horizontal direction. On a brightness scale of 0 (darkest color) to 255 (brightest color) on the Macintosh standard 13-in. monitor, the average pixel value of the mask was $127 .{ }^{3}$ The stimuli were presented at a brightness value of 83 (approximately $1 / 3$ of the maximum). Hence, the stimuli were slightly darker than the average value of the masking background.

The position of the stimulus string was randomly varied horizontally by \pm 11 pixels in single-pixel steps.

\section{Results and Discussion}

The subjects were more accurate at identifying letters in words as opposed to nonwords $(80.2 \%$ vs. $75.5 \%)$. This difference was reliable, with subjects as the random variable $[F(1,11)=25.45, p<.001]$. Because the stimulus was randomly selected on each trial, and there were unequal numbers of trials for the eight words and nonwords, an analysis with items as the random variable was not performed.

With so few stimuli, letter position is confounded with specific letter discrimination. For both words and nonwords, R-P was the most difficult letter pair to discrimi- 

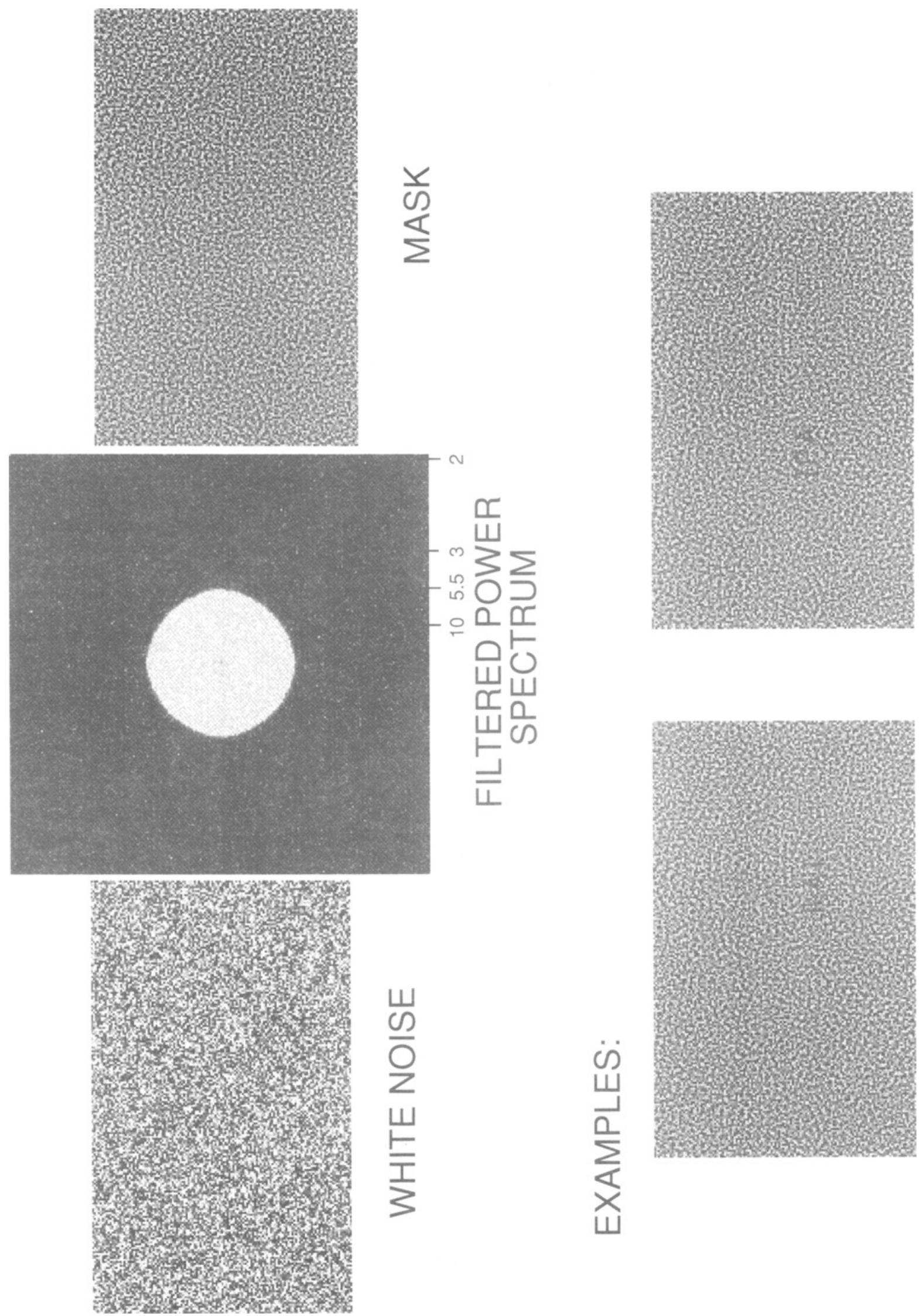
nate $(63.6 \%$ correct), followed by $\mathrm{N}-\mathrm{T}$ and $\mathrm{A}-\mathrm{U}$ ( $84.3 \%$ and $85.7 \%$, respectively).

Experiment 6 opens up the-possibility of asking whether specific spatial frequencies are more important for word perception. It is reasonable to assume that if the mask and the stimulus are similar, performance will be worse than it will if they are dissimilar. It might be that the WSE will be greater when the mask contains spatial frequencies that are critical for identifying single letters, but not frequencies that are critical for perception of the word. Parish and Sperling (1987) have shown that the most important frequencies for identifying a single letter are those near the height of the letter. The optimal frequencies for words may be different. For example, for words, frequencies corresponding to the width of the word might be important. If the mask contains frequencies that interfere with letters more than with words, one might obtain a larger WSE than one would otherwise. In this experiment, low frequencies were removed from a white-noise mask, leaving only high frequencies. The notion is that the high frequencies in the mask may have more of a detrimental effect on the perception of letters than they have on the perception of words. From the present experiment alone, it is not possible to determine whether the specific frequency characteristics of the mask make a difference for the word-nonword effect. It will be necessary to test other masks that systematically differ in spatial frequency. Questions about spatial frequency cannot be asked with a T-scope paradigm, because a brief exposure is, in effect, a lowpass filter.

\section{GENERAL DISCUSSION}

The goal of this research was to determine whether one could obtain a WSE without using brief stimulus exposures and/or a poststimulus pattern mask. With very small stimuli, subjects were more accurate at detecting target letters in words than they were at detecting target letters in nonwords. With a simultaneous pattern mask, performance was better with words than with single letters. Finally, with a mask consisting of mostly high-frequency noise, letter recognition was superior with words as opposed to nonwords. Apparently, brief exposures and/or a poststimulus mask are not necessary for the occurrence of a WSE.

Although the word-nonword and word-single-letter effects are more general than has previously been supposed, there are undoubtedly many interesting boundary conditions. In the discussion of Experiment 3, for example, it was pointed out that when the stimuli are very small, subjects are better at detecting single letters than they are at detecting words. Thus, there may be stimulus conditions that lead to a word-nonword effect, but not a word-letter effect. Similarly, there may be conditions with brief exposures that lead to a word-nonword effect but not to a word-single-letter effect. Indeed, demonstrating a WSE without the use of brief exposures raises a number of questions that have been hidden with the use of brief exposures.
In the typical experiment with a brief exposure and a pattern mask, a number of factors could differentially affect performance with words, nonwords, and single letters. First, the onset of the stimulus may generate transient visual signals that draw attention to some kinds of stimuli (see, e.g., Yantis \& Jonides, 1990). Obviously, with a brief exposure, processing time is limited. However, the brief exposure not only affects processing time, but also reduces contrast and operates as a lowpass spatial frequency filter. The offset of the stimulus and the onset of the mask would generate additional transient signals. Finally, a poststimulus mask may cause interrupting masking or integration masking. The integration of the stimulus and mask would add contours to the target letter, thus increasing lateral masking for single letters. Integration of the mask and stimulus may also create a figure-ground problem, making some stimuli difficult to find or to segregate from the mask. Interruption masking may have different effects at different levels of representation (Johnston \& McClelland, 1980).

It is impossible to disentangle these factors with the use of brief exposures. For example, consider an experiment in which Johnston and McClelland (1973) used brief exposures. They compared the WSE with a pattern mask and with reduced contrast. However, the exposure durations used with the pattern mask were well within the range in which contrast is also reduced (the exposure durations averaged $31 \mathrm{msec}$ ). Thus the use of brief exposures and/or a mask inherently confounds a number of stimulus factors. With an unlimited exposure, it is possible to isolate, for example, the effects of contrast or spatial frequency. It may be that the WSE only emerges under some stimulus conditions. Alternatively, the wordnonword effect and word-letter effect may arise under different stimulus conditions that are confounded in the typical experiment.

Isolating the stimulus conditions necessary for the wordnonword or word-single-letter effects would seem to be a logical first step in the attempt to understand these phenomena. Of course, we also need to specify a processing model that affords words an advantage. Numerous models have been proposed, and they differ in the source of information that subjects utilize in recognizing words and letters. It has been proposed that subjects use information about shapes of words or letter clusters (e.g., Smith, 1971). Others postulate that lexical information preferentially activates letters in words (McClelland \& Rumelhart, 1981; Paap, Newsome, McDonald, \& Schvaneveldt, 1982). Finally, words may have an advantage in processing because they contain recognizable clusters of letters (see, e.g. , Richman \& Simon, 1989).

It may be that more than one source of information is used for recognizing letters in words (also see Prinzmetal, Hoffman, \& Vest, 1991; Prinzmetal, Treiman, \& Rho, 1986). Object recognition is something in which humans excel, and word recognition is a kind of object recognition. It would be surprising if we used only one kind of information for recognizing objects. Consider, for exam- 
ple, another visual ability at which humans are adept: depth perception. We use numerous sources of information to determine depth, such as binocular disparity, accommodation, relative size, linear perspective, and many others. By analogy, we may use several sources of information for recognizing letters in words. Most present theories stress single sources of information.

If several sources of information do contribute to the WSE, it will be easier to demonstrate that a source of information is used than to show that a source of information is not used. For example, McClelland (1976) found a WSE with mixed-case stimuli (e.g., wOrD). He concluded that visual features associated with word wholes or letter clusters were not important for the WSE. However, if several sources of information are used for the recognition of letters in words, eliminating one of them will not necessarily eliminate the effect. In the case of depth perception, it would be a mistake to conclude that binocular disparity was not important because subjects could make accurate depth judgments monocularly. Thus, proving the null hypothesis will be especially difficult if multiple sources of information contribute to the WSE.

If we consider the WSE to be an example of object recognition, perhaps it is not surprising that the WSE can be obtained in a variety of situations. It is encouraging to know that the WSE generalizes to vision outside the use of the T-scope, because theories of the WSE may have wider application to problems in object recognition, and conversely, because advances in object recognition may shed light on word perception. The methods employed in the present research will make it possible to disentangle a variety of factors that are compounded in the typical T-scope experiment.

Finally, there are other perceptual effects in which the configuration of the whole affects processing. In all of these effects, the stimuli are presented briefly and are usually followed by a visual noise mask. For example, Doyle and Leach (1988) presented either a blank field or a stimulus, followed by a mask. Subjects were more accurate at detecting the presence/absence of the stimulus with words than with nonwords (word-detection effect). The object-superiority effect is the finding that subjects are more accurate at identifying a target line in coherent threedimensional stimuli than in less coherent two-dimensional forms (Weisstein \& Harris, 1974). In the object-detection effect, the coherence of the stimulus as a whole affects presence/absence detection thresholds (Purcell \& Stewart, 1991). Similarly, there are a face-superiority effect (Homa, Haver, \& Schwartz, 1976; Mermelstein, Banks, \& Prinzmetal, 1979) and a face-detection effect (Purcell \& Stewart, 1988). It will interesting to know whether these other configuration effects can be obtained outside of the use of the T-scope.

\section{REFERENCES}

Banks, W. P., Larson, D. W., Prinzmetal, W. (1979). Asymmetry of visual interference. Perception \& Psychophysics, 25, 447-456. BARON, J., \& ThURSTON, I. (1973). An analysis of the word-superiority effect. Cognitive Psychology, 4, 207-228.
BJoRk, E. L., Estes, W. K. (1973). Letter identification in relation to linguistic context and masking conditions. Memory \& Cognition, 1, 217-223.

BoumA, H. (1973). Visual interference in the parafoveal recognition of initial and final letters of words. Vision Research, 13, 767-782.

CATtELL, J. M. (1885). The inertia of the eye and brain. Brain, 8 , 295-312.

Chastain, G. (1986). Word-to-letter inhibition: Word-inferiority and other interference effects. Memory \& Cognition, 14, 361-368.

DoDge, R. (1907). An experimental study of visual fixation. Psychological Review Monograph Supplements, 8(4), 1-95.

DoYLE, J. R., LEACH, C. (1988). Word superiority in signal detection: Barely a glimpse, yet reading nonetheless. Cognitive Psychology, 20, 283-318.

DunCan, J. (1983). Category effects in visual search: A failure to replicate the "oh-zero" phenomenon. Perception \& Psychophysics, 34, 221-232.

Erdmann, B., Dodge, R. (1897). Psychologische Untersuchungen uber das Lesen, auf experimenteller Grundlage. Halle.

ERIKSEN, B. A., ERIKSEN, C. W. (1974). The importance of being first: A tachistoscopic study of the contribution of each letter to the recognition of four-letter words. Perception \& Psychophysics, 15 , 66-72.

ERIKSEN, C. W. (1980). The use of a visual mask may seriously confound your experiment. Perception \& Psychophysics, 28, 89-92.

Eriksen, C. W., Collins, J. F. (1967). Some temporal characteristics of visual pattern perception. Journal of Experimental Psychology, 74, 476-484.

ERIKSEN, C. W., Coluns, J. F. (1968). Sensory traces versus the psychological moment in the temporal organization of form. Joumal of Experimental Psychology, 77, 367-382.

ERIKSEN, C. W., Hoffman, J. E. (1973). The extent of processing of noise elements during selective encoding from visual displays. Perception \& Psychophysics, 14, 155-160.

Flom, M. C., Weymouth, F. W., \&ahneman, D. (1963). Visual resolution and contour interaction. Joumal of the Optical Society of America, 53, 1026-1032.

GleitmaN, H., Jonides, J. (1978). The effect of set on categorization in visual search. Perception \& Psychophysics, 24, 361-368.

Hock, H. S., Rosenthal, A., Stenquist, P. (1985). The category effect in visual search: Practice effects on catch trials. Perception \& Psychophysics, 37, 73-80.

Homa, D., Haver, B., Schwartz, T. (1976). Perceptibility of schematic face stimuli: Evidence for a perceptual Gestalt. Memory \& Cognition, 4, 176-185.

HUEY, E. B. (1908). The psychology and pedagogy of reading. New York: Macmillan.

JoHNSTON, J. C. (1981a). Effects of advance precuing of alternatives on the perception of letters alone and in words. Joumal of Experimental Psychology: Human Perception \& Performance, 7, 560-572.

Johnston, J. C. (1981b). Understanding word perception: Clues from studying the word-superiority effect. In O. Tzeng \& H. Singer (Eds.), Perception of print: Reading research in experimental psychology (pp. 65-84). Hillsdale, NJ: Erlbaum.

JohNSTON, J. C., \& MCCLELLAND, J. L. (1973). Visual factors in word perception. Perception \& Psychophysics, 14, 365-370.

Johnston, J. C., MCClelland, J. L. (1974). Perception of letters in words: Seek not and ye shall find. Science, 184, 1192-1194.

Johnston, J. C., \& MCClelland, J. L. (1980). Experimental tests of a hieranchical model of word identification. Joumal of Verbal Leaming \& Verbal Behavior, 19, 503-524.

Jonides, J., Gleitman, H. (1972). A conceptual category effect in visual search: $O$ as letter or as digit. Perception \& Psychophysics, $12,457-460$.

KATZ, D. (1989). The world of touch (L. Krueger, Trans.). Hillsdale, NJ: Erlbaum. (Original work published 1925)

KRUEGER, L. E. (1970). Search time in a redundant visual display. Journal of Experimental Psychology, 83, 391-399.

KRUEGER, L. E. (1975). The word-superiority effect: Is its locus visualspatial or verbal? Bulletin of the Psychonomic Society, 6, 465-468. Krueger, L. E., Keen, R. H., Rublevich, B. (1974). Letter search 
through words and nonwords by adults and fourth-grade children. Journal of Experimental Psychology, 102, 845-849.

KrUEger, L. E., \&HAPIRo, R. G. (1979). Letter detection with rapid serial visual presentation: Evidence against word superiority at feature extraction. Joumal of Experimental Psychology: Human Perception \& Performance, 5, 657-673.

LEEPER, R. (1935). A study of a neglected portion of the field of learning -the development of sensory organization. Joumal of Genetic Psychology, 46, 41-75

Loomis, J. M. (1978). Lateral masking in foveal and eccentric vision. Vision Research, 18, 335-338.

MARChETtI, F. M., MEWHORT, D. J. K. (1986). On the wordsuperiority effect. Psychological Research, 48, 23-35.

MCClelland, J. L. (1976). Preliminary letter identification in the perception of words and nonwords. Journal of Experimental Psychology: Human Perception \& Performance, 2, 80-91.

McClelland, J. L., \& Rumelhart, D. E. (1981). An interactive activation model of context effects in letter perception: Part 1. An account of basic findings. Psychological Review, 88, 375-407.

Mermelstein, R., Banks, W., \& Prinzmetal, W. (1979). Figural goodness effects in perception and memory. Perception \& Psychophysics, 26, 472-480.

PAAP, K. R., Newsome, S. L. (1980). A perceptual-confusion account of the WSE in the target search paradigm. Perception \& Psychophysics, 27, 444-456.

PaAp, K. R., Newsome, S. L., McDonald, J. E., \& Schvaneveldt, R. W. (1982). An activation-verification model for letter and word recognition: The word-superiority effect. Psychological Review, 89, 573-594.

Parish, D. H., Speruing, G. (1987). Object spatial frequency, not retinal spatial frequency, determines identification efficiency. Investigative Ophthalmology \& Visual Science, 28(Suppl.), 359.

Pillsbury, W. B. (1897). A study in apperception. American Journal of Psychology, 8, 315-393

Prinzmetal, W., Hoffman, H., \& Vest, K. (1991). Automatic processes in word perception: An analysis from illusory conjunctions. Joumal of Experimental Psychology: Human Perception \& Performance, 4, 902-923.

Prinzmetal, W., Treiman, R., Rho, S. H. (1986). How to see a reading unit. Journal of Memory \& Language, 25, 461-475.

PurCell, D. G., STEWART, A. L. (1988). The face-detection effect: Configuration enhances detection. Perception \& Psychophysics, 43, 355-366.

Purcell, D. G., \& Stewart, A. L. (1991). The object-detection effect: Configuration enhances perception. Perception \& Psychophysics, 50, 215-224

REICHER, G. M. (1969). Perceptual recognition as a function of meaningfulness of stimulus material. Joumal of Experimental Psychology, 81, 275-280.

Richman, H. B., \&imon, H. A. (1989). Context effects in letter perception: Comparison of two theories. Psychological Review, 96, 417-432.

Rumelhart, D. E., \& MCClelland, J. L. (1982). An interactive activation model of context effects in letter perception: Part 2 . The contextual enhancement effect and some tests and extensions of the model. Psychological Review, 89, 60-94.

SANTEE, J. L., \& EgETh, H. E. (1980). Interference in letter identification: A test of feature-specific inhibition. Perception \& Psychophysics, 27, 321-330.

SMITH, F. (1971). Understanding reading. New York: Holt, Rinehart \& Winston.

Thompson, M. C., Massaro, D. W. (1973). Visual information and redundancy in reading. Joumal of Experimental Psychology, 98, 49-54.

Townsend, J. T., TAYLOR, S. G., Brown, D. R. (1971). Lateral masking for letters with unlimited viewing time. Perception \& Psychophysics, 10, 375-378.

TuRveY, M. T. (1973). On peripheral and central processes in vision:
Inferences from an information-processing analysis of masking. Psychological Review, 80, $1-52$

WeISSTEIN, N., \& HARRIS, C. S. (1974). Visual detection of line segments: An object-superiority effect. Science, 186, 752-755.

WOODWORTH, R. S. (1938). Experimental psychology. New York: Harcourt, Brace

Yantis, S., Jonides, J. (1990). Abrupt onsets and selective attention: Voluntary versus automatic allocation. Journal of Experimental Psychology: Human Perception \& Performance, 16, 121-134.

\section{NOTES}

1. Huey (1908) claimed that Erdmann and Dodge (1897) found that words were easier to identify at a distance than single letters were. Huey reported, "Erdmann and Dodge found that words could be recognized at a distance from the reader which made the constituent letters unrecognizable when presented singularly" (p. 62). However, as will be reported later, in pilot experiments with words and single letters compared by themselves, I have always found that single letters (without lateral flanking characters) are much easier to identify than letters in words. (In Experiments 1-3, single letters were always presented with flanking characters.) I have had sections of Erdmann and Dodge (1897) translated, but I cannot account for the discrepancy. Without a complete translation of their entire book, however, I cannot confidently claim to understand the details of their observation. Nevertheless, Erdmann and Dodge should be credited with having first suggested the presentation of words at a distance.

2. The computer programs used to run the experiments reported in this paper can be obtained from the author. They were written in LightSpeed Pascal, and both the source code and compiled versions are available. To receive them, please send a blank 3.25 -in. disk and an appropriate self-addressed stamped envelope to the author.

3 . The scale $0-255$ is approximately linearly related to foot-lamberts.

APPENDIX

\begin{tabular}{|c|c|c|c|}
\hline 1st Position & 2nd Position & 3rd Position & 4th Position \\
\hline PARK & FARM & STEP & FILM \\
\hline MARK & FIRM & STOP & FILE \\
\hline FAST & BOAT & ROLE & HOLE \\
\hline VAST & BEAT & ROSE & HOLY \\
\hline WINE & WORE & TEAM & DEAR \\
\hline MINE & WIRE & TERM & DEAN \\
\hline NOSE & SLOW & SHIP & MAIL \\
\hline LOSE & SNOW & SHOP & MAID \\
\hline LAKE & BAND & JURY & CAST \\
\hline SAKE & BOND & JULY & CASH \\
\hline GOLD & MILE & PAGE & MEAT \\
\hline SOLD & MALE & PALE & MEAL \\
\hline GATE & LUCK & WIND & COAT \\
\hline FATE & LOCK & WILD & COAL \\
\hline DREW & LOAN & SAVE & PACE \\
\hline GREW & LEAN & SALE & PACK \\
\hline YARD & CORE & WAGE & WEAR \\
\hline CARD & CURE & WAVE & WEAK \\
\hline CORN & FAIL & PICK & FISH \\
\hline HORN & FOIL & PINK & FIST \\
\hline GIFT & GOLF & RIDE & BARE \\
\hline LIFT & GULF & RICE & BARN \\
\hline SANK & COPE & BENT & FLED \\
\hline RANK & CAPE & BELT & FLEW \\
\hline
\end{tabular}

(Manuscript received August 26, 1991; revision accepted for publication January 6,1992 .) 